\title{
MULTITEMPORAL 3D MAPPING OF POST-EARTHQUAKE RECOVERY PHASE WITH UAS: CASE STUDY VRISA, LESVOS, GREECE
}

\author{
G. Tataris ${ }^{1}$, N. Soulakellis ${ }^{1 *}$, K. Chaidas ${ }^{1}$ \\ ${ }^{1}$ Department of Geography, University of the Aegean, Mytilene, Greece (tataris@geo.aegean.gr; nsoul@aegean.gr; \\ k.chaidas@aegean.gr)
}

Commission IV

KEY WORDS: Post-earthquake, Recovery Phase, 3D mapping, Building Demolition, Lesvos Earthquake, UAS

\begin{abstract}
:
The recovery phase of an earthquake-affected settlement is a time-consuming and complex process that requires monitoring, which is now possible using UAS. The purpose of this paper is to present the methodology followed and the results obtained by the exploitation of UAS for rapid multitemporal 3D mapping during the recovery phase of Vrisa traditional settlement, Lesvos island, Greece, which was highly damaged by the earthquake $(\mathrm{Mw}=6.3)$ on $12^{\text {th }}$ June 2017. More analytically, three (3) flight campaigns covering the period July 2017 - May 2020 took place by means of an UAS for collecting high-resolution images on: i) $19^{\text {th }}$ May 2019, ii) $29^{\text {th }}$ September 2019, iii) $17^{\text {th }}$ May 2020. Structure from Motion (SfM) and Multi Stereo View (MSV) methods have been applied and produced: i) Digital Surface Models - DSMs, ii) 3D Point Clouds - 3DPC and iii) Orthophoto-maps, of Vrisa. In parallel, GIS capabilities has been exploit to calculate building volumes based on: a) DSM produced by UAS image processing, b) DEM produced by 233 RTK measurements and c) building footprints derived by the digitization of the orthophotomap of $25^{\text {th }}$ July 2017. The methodology developed and implemented achieves extremely reliable results in a relatively easy, fast and economically feasible way, which is confirmed with great precision by field work. By applying the above-described methodology, it was possible to monitoring the recovery phase during July 2017 and May 2020 which $302 / 340$ buildings that had been severely damaged by the earthquake have been demolished. A small number of new buildings have also been rebuilded and small number of buildings that have just begun excavations for their construction. An important parameter for obtaining reliable data and comparable results is the correct selection of flight parameters and their maintenance at all times when it is decided to take data, without affecting the accuracy of the results from taking photos or videos. Automation in the future of the proposed methodology can significantly accelerate the achievement of reliable results without the intermediate interpretation of orthophoto-maps.
\end{abstract}

\section{INTRODUCTION}

Several studies worldwide reveal the significance of UAS capabilities for 3D mapping during an emergency and especially shortly after an earthquake (Adams and Friedland, 2011).

In cases where there is a large number of heavily damaged buildings, dangerous and unrepairable there is a great need for their demolition. The demolition process is taking place during the recovery phase of a natural disaster and is crucial to be mapped to monitor and document its progress.

UAS proved to be a safe, cost effective technology for rapid 3D mapping of the effects of a natural disaster to manmade structures (Huang et al 2017). Especially, building damage assessment as a result of an earthquake activity by the exploitation of high-resolution images acquired by UAS has a great research interest worldwide. Structure from Motion (SfM) and Multi Stereo View (MSV) methods provide accurate and reliable geospatial 3D information and more analytically 3D Point Clouds (3DPC), Digital Surface Models (DSM) and orthophoto-maps.

The use of remote sensing in emergency situations offers several advantages, the first and foremost is the investigation and information acquisition in extremely dangerous zones. At first, for an 'early damage assessment', the high-resolution images are very useful to detect quickly the areas and structures that suffered the worst damages (Baiocchi et al. 2012; Tong et al. 2012), but for a complete and detailed survey of structures and infrastructures, useful for the following reconstruction phase, the Unmanned Aerial Vehicle (UAV) photogrammetry technique is more suitable (Xu et al. 2014)

Despite the fact that 3D modelling and mapping by means of UAS high-resolution images is rapidly expanding to address the needs of a post-earthquake situation, there is no robust methodology to apply for monitoring the building demolition and reconstruction process that occurs during the recovery phase.

\subsection{Study area}

Vrisa traditional village, on the south-eastern coast of Lesvos island, Greece, was partially ruined by a devastated earthquake (magnitude $\mathrm{Mw}=6.3$ ), on 12th June 2017 (UTC 12:28:38.26) (Kiratzi, 2018, Papadimitriou P., et al 2018) (Figure 1).

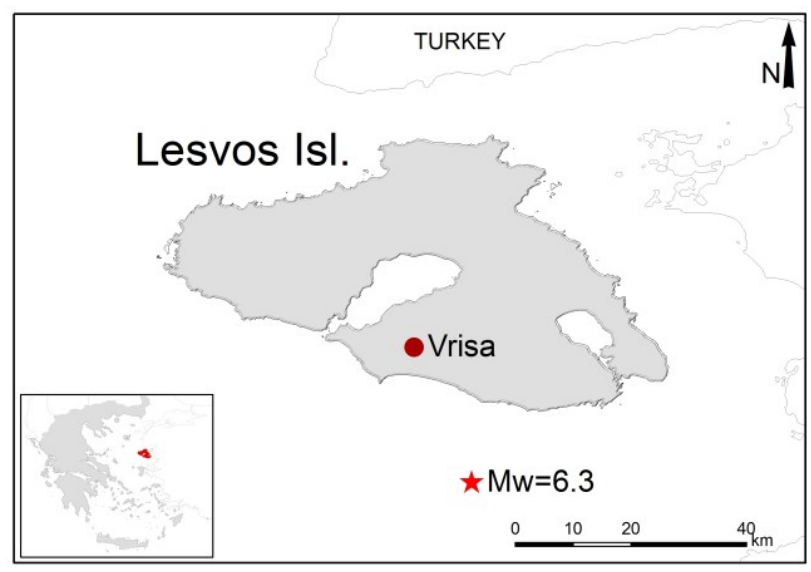

Figure 1. The epicenter of the earthquake of 12th June 2017, near the coast of Lesvos, which destroyed a part of the traditional settlement of Vrisa.

The main factors controlling the spatial distribution of building damages are the geological and geomorphological setting along 
with the building characteristics. Specifically, the combination of old masonry structures founded on alluvial deposits in an area bounded by significant faults in combination with probable directivity phenomena resulted in destruction (Lekkas et al. 2017).

Damaged buildings belonging into scales 4 (very heavy damage: heavy structural damage, very heavy non-structural damage) and 5 (destructive: very heavy structural damage), according to the EMS-98, should be demolished by their owners while all the rest ones should be repaired. Practically, almost 340 out of 1100 buildings of Vrisa traditional settlement should be demolished and reconstructed.

On $25^{\text {th }}$ July 2017, an UAS (hexacopter) flew over the Vrisa village at $65 \mathrm{~m}$ altitude and captured vertical and oblique images using a Canon camera with a fixed lens of $28 \mathrm{~mm}$ focal length for nadir images and three IXUS 160 cameras with a fixed lens of $6.16 \mathrm{~mm}$ focal length for oblique images (Soulakellis et al 2019). The significant results obtained were the orthophoto-map and the DSM (25th July 2017).

The July $25^{\text {th }}$ orthophoto-map (Figure 2) fully presents the condition of the buildings in the settlement a few weeks after the earthquake. About a third of the settlement's buildings have been severely damaged and need immediate demolition a third of the settlement's buildings have suffered minor damage and need to be repaired, and only a third of the settlement's buildings have not been damaged.

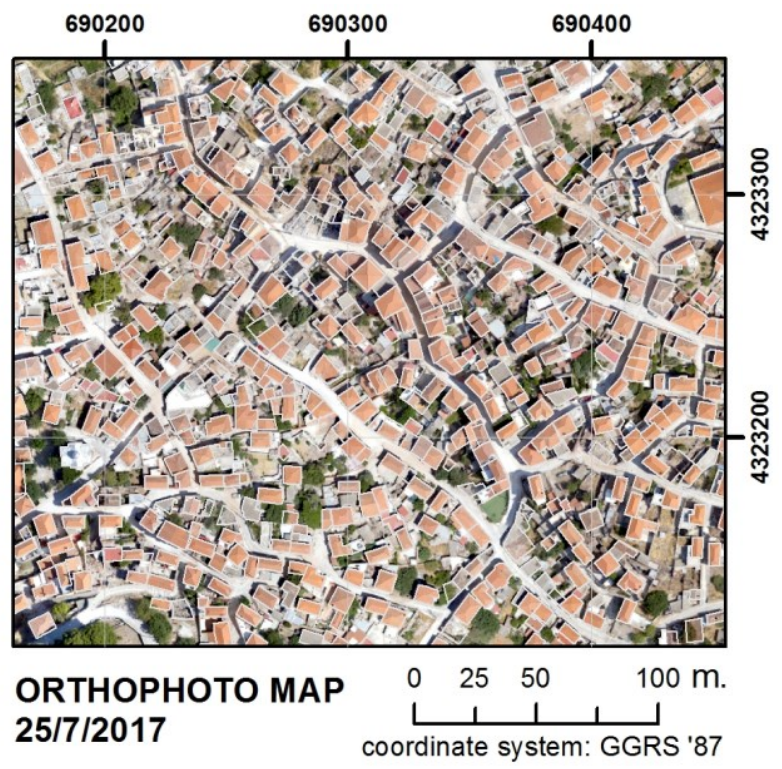

Figure 2 . The $25^{\text {th }}$ July 2017 orthophoto-map. Only along the roads have the debris been removed to facilitate traffic throughout the settlement while all the other wreckage of the earthquake is around the destroyed houses.

Due to its high-resolution, the DSM on July 25 (Figure 3) accurately shows the heights of the buildings just as they were formed immediately after the earthquake and in this way, they allow future mapping of their changes based on the changes in their volume during the recovery face.

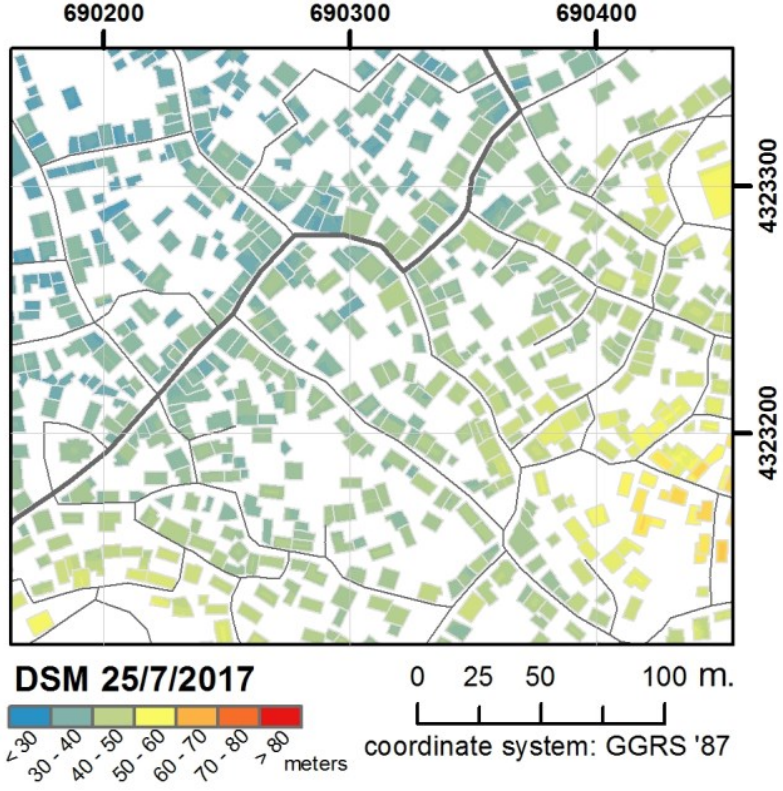

Figure 3 . The $25^{\text {th }}$ July 2017 DSM accurately presents the settlement's buildings height.

\section{METHODOLOGY}

The methodology of the present paper entails three steps:

- $\quad$ UAS data acquisition and 3D modelling on three different epochs:

i. $19^{\text {th }}$ May 2019 ,

ii. $29^{\text {th }}$ September 2019 and

iii. $17^{\text {th }}$ May 2020)

- $\quad$ DSM difference and building volume calculation and

- $\quad$ Evaluation of the results based on field work and visualization of the changes occurred during the postearthquake recovery phase.

The sequence of the methodology is portrayed in Figure 4.

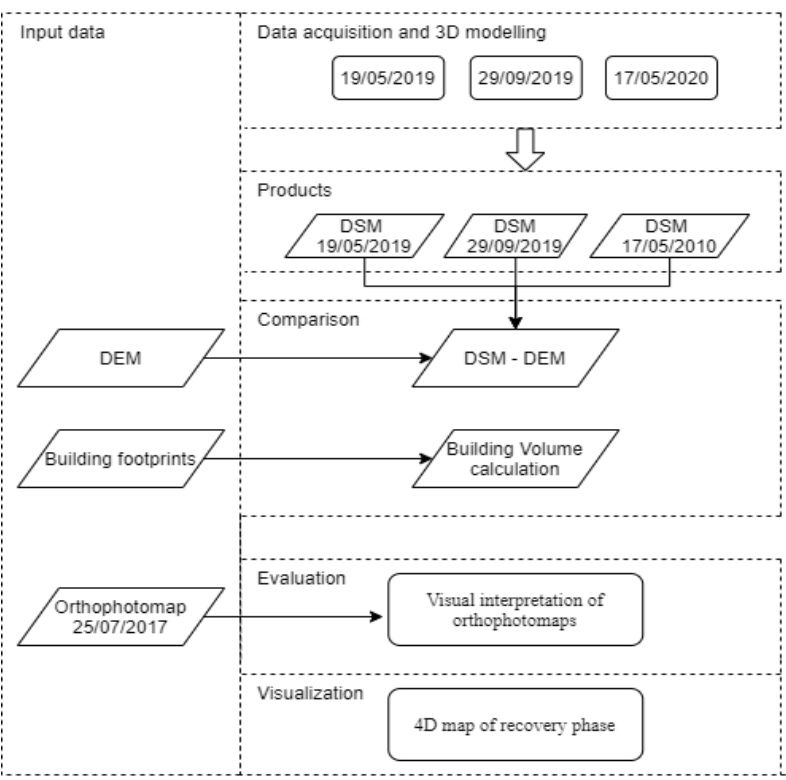

Figure 4. Flow chart of the methodology followed for monitoring and mapping the recovery phase at Vrisa settlement after the destructive earthquake. 


\subsection{UAS data acquisition and 3D modelling}

Aiming to map the progress of post-earthquake recovery phase of Vrisa settlement, three (3) flight campaigns have been performed on:
i. $\quad 19^{\text {th }}$ May 2019,
ii. $\quad 29^{\text {th }}$ September 2019 and
iii. $\quad 17^{\text {th }}$ May 2020.

As dates for these flights, the beginning and the end of the summer were chosen, which is the best period for construction activity.

Flight planning has been performed in the lab with dedicated software (Litchi Hub) and crucial flight parameters have been decided. More analytically:

- $\quad$ Flight height: the altitude of $85 \mathrm{~m}$ and flight speed of $25 \mathrm{~km} / \mathrm{h}$ proved to be the most suitable for the specific study area, approximately $0.27 \mathrm{~km}^{2}$. This height and flight speed was obtained because the flight duration of a UAS battery is about $20 \mathrm{~min}$, it had to be done with one flight and the GSD were calculated to be approximately $2.5-3 \mathrm{~cm} / \mathrm{pix}$.

Flight path: for reaching the specific research goals a flight plan was designed, using Litchi Mission hub software, taken into consideration the orientation of the street network by following flight paths that are parallel mainly to the main streets and having $50 \mathrm{~m}$ distance among them, providing a $50 \%$ side overlapping.

Front overlapping: for the needs of the present research a $70 \%$ front overlapping has been decided.

On the flights $19^{\text {th }}$ May 2019 and $29^{\text {th }}$ September 2019, a video was shoot, then video frames extracted every $2 \mathrm{sec}$ and on flight $17^{\text {th }}$ May 2020, images were shooting every $3 \mathrm{sec}$.

\begin{tabular}{|c|c|c|c|c|}
\hline \multirow{4}{*}{ Flight } & Date & $19 / 5 / 2019$ & $29 / 9 / 2019$ & $17 / 5 / 2020$ \\
\hline & Time (local) & $11: 30$ p.m. & 12:30 p.m. & 12:30 p.m. \\
\hline & \begin{tabular}{|l|} 
Duration \\
\end{tabular} & $20 \mathrm{~min}$ & $20 \mathrm{~min}$ & $20 \mathrm{~min}$ \\
\hline & Altitude & $85 \mathrm{~m}$. & $85 \mathrm{~m}$. & $85 \mathrm{~m}$. \\
\hline \multirow{2}{*}{ Type of UAV } & & Phantom 4 Pro & Phantom 4 Pro & Phantom 4 Pro \\
\hline & Weight with Lens & $1.4 \mathrm{kgr}$ & $1.4 \mathrm{kgr}$ & $1.4 \mathrm{kgr}$ \\
\hline \multirow{5}{*}{ Optical Sensor } & camera & $\mathrm{FC6310}$ & FC6310 & $\mathrm{FC6310}$ \\
\hline & Effective Pixels & $16.8 \mathrm{MP}$ & $16.8 \mathrm{MP}$ & $16.8 \mathrm{MP}$ \\
\hline & \begin{tabular}{|l} 
Focal Length \\
\end{tabular} & $8 \mathrm{~mm}$ & $8 \mathrm{~mm}$ & $8 \mathrm{~mm}$ \\
\hline & Sensor dimensions & Width: $13.2 \mathrm{~mm}$ & Width: $13.2 \mathrm{~mm}$ & Width: $13.2 \mathrm{~mm}$ \\
\hline & Pixel dimension & $2.53 \times 2.53 \mu . \mathrm{m}$ & $2.53 \times 2.53 \mu . \mathrm{m}$ & $2.53 \times 2.53 \mu . \mathrm{m}$ \\
\hline FOV direction & & nadir & nadir & nadir \\
\hline GSD & & $2.28 \mathrm{~cm} / \mathrm{pix}$ & $2.28 \mathrm{~cm} / \mathrm{pix}$ & $2.28 \mathrm{~cm} / \mathrm{pix}$ \\
\hline \multirow{2}{*}{$\begin{array}{l}\text { Overlaping of } \\
\text { photographs }\end{array}$} & Longitudinal & $70 \%$ & $70 \%$ & $70 \%$ \\
\hline & Side lap & $50 \%$ & $50 \%$ & $50 \%$ \\
\hline $\begin{array}{l}\text { Number of } \\
\text { photographs }\end{array}$ & Nadir & 931 from video/2 sec & 862 from video/2 sec & 431 \\
\hline Total area & & $0.269 \mathrm{~km}^{2}$ & $0.268 \mathrm{~km}^{2}$ & $0.271 \mathrm{~km}^{2}$ \\
\hline
\end{tabular}

Table 1. Flight planning parameters for UAS image acquisition.

To reference the model in the Greek projection system (GGRS 1987) in the three (3) flight campaigns, were used 10 Ground Control Points (GCPs), which were measured with the RTK method.

The Structure from Motion (SfM) and Multi View Stereo (MVS) algorithms are widely used for creating 3D point clouds and DSM - digital surface models from a set of 2D images acquired by UAS. The Photoscan/Agisoft software has been used to process the UAS images and to produce the following results: a) Orthophoto-maps $17^{\text {th }}$ May 2020 (Figures 5) and b) Digital Surface Models - DSM of $17^{\text {th }}$ May 2020 (Figures 6).

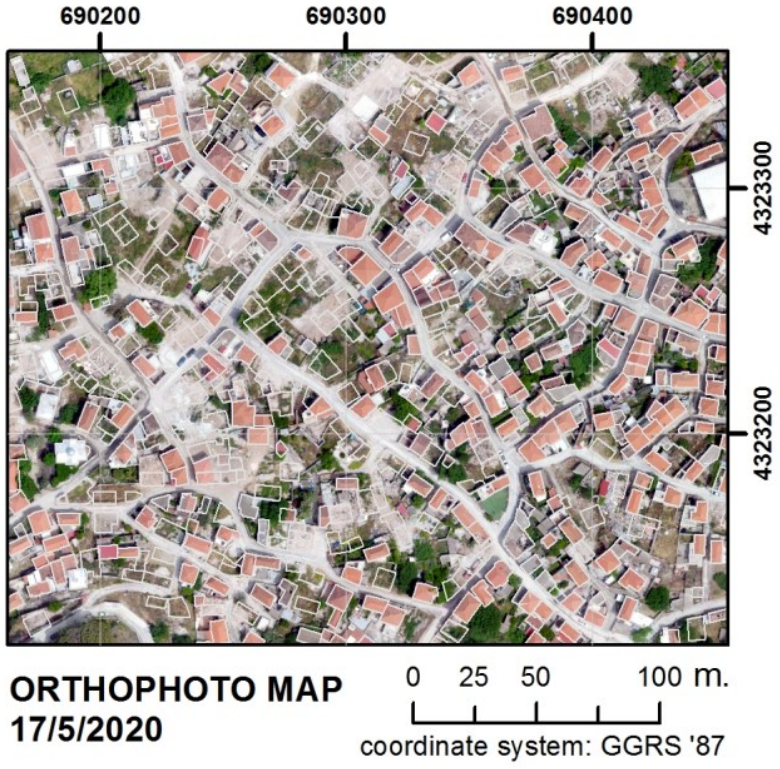

Figure 5. Orthophoto-map derived by UAS high-resolution images acquired on $17^{\text {th }}$ May 2020. It clearly presents the changes occurred and more specifically the begin of the rebuilding process.

Visual interpretation of the orthophoto-maps reveals the significant progress of building demolition during 2018, 2019 and early 2020. Most of the demolished buildings appear on $19^{\text {th }}$ May 2019 while only two buildings have been rebuilt. During the summer period of 2019 more damaged buildings demolished appeared by interpreting the $29^{\text {th }}$ September 2019 orthophoto-map. Finally, on $17^{\text {th }}$ May 2020 several new rebuilds are presented and excavations for starting new building constructions.

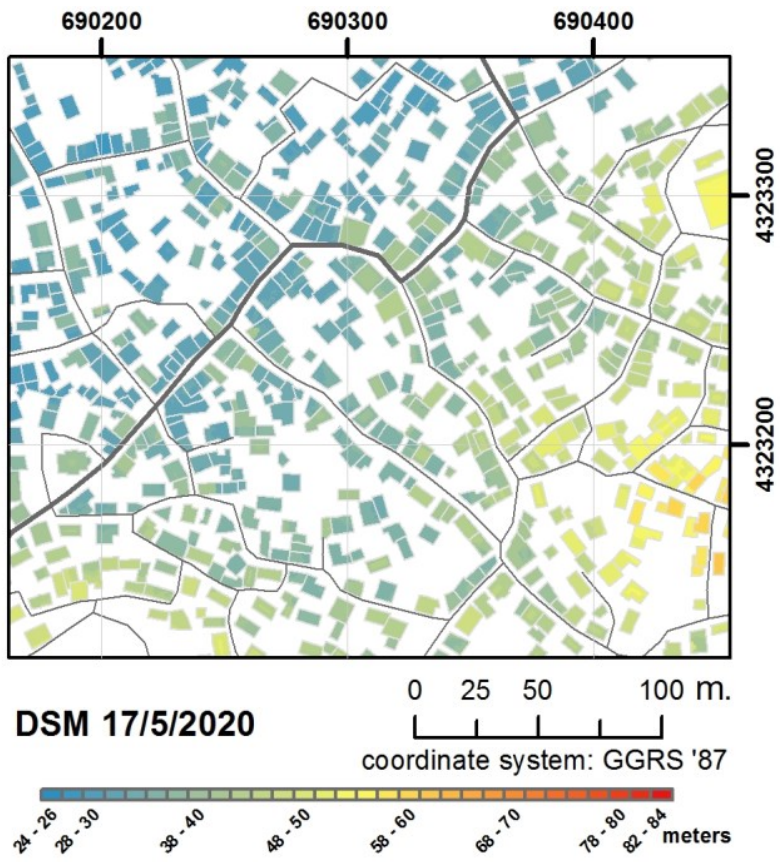

Figure 6. The DSM map derived by UAS high-resolution images acquired on 17th May 2020. 
Visual interpretation of the DSM difference maps reveals the significant reduction of the demolished building heights. Most of the demolished buildings appear on $19^{\text {th }}$ May 2019 while only two buildings have been rebuilt. During the summer period of 2019 more damaged buildings demolished and can be mapped by interpreting the $29^{\text {th }}$ September 2019 orthophotomap. Finally, on $17^{\text {th }}$ May 2020 several new rebuilds are presented and new excavations for starting new building constructions.

\subsection{DSM difference and building volume calculation}

The multitemporal monitoring of the buildings volume, as calculated by their 3D mapping using UAS, is an important indicator of monitoring the post-earthquake recovery phase of a traditional settlement. However, in order to better understand the changes in the building volumes, it is necessary to have a good knowledge of the areas that the buildings present in the specific settlement of Vrisa. More analytically, the traditional settlement of Vrisa consists mostly of small ( $>100$ sq.m.) to medium (100-150 sq.m.) single-storey and two-storey buildings with roofs. The average floor height is about 3 meters while the average height of the roofs is 1.5 meters.

During the present study three high-resolution $(11 \mathrm{~cm})$ Digital Surface Models has been created by 233 Ground Control Points (GCPs), which were measured with the RTK method, presenting the heights of Vrisa traditional village surface at three different epochs: i) $19^{\text {th }}$ May 2019, ii) $29^{\text {th }}$ September 2019 and iii) $17^{\text {th }}$ May 2020. By subtracting the available Digital Elevation Model high-resolution $(10 \mathrm{~cm})$ from the DSMs (DEM - DSM), four DSM of difference maps have been created showing the dramatic changes of height values into the demolished buildings footprints (Figure 7). These four DSMs of difference were further processed by exploiting GIS capabilities to calculate the buildings volume at four different epochs (Figure 8,9,10 and 11).
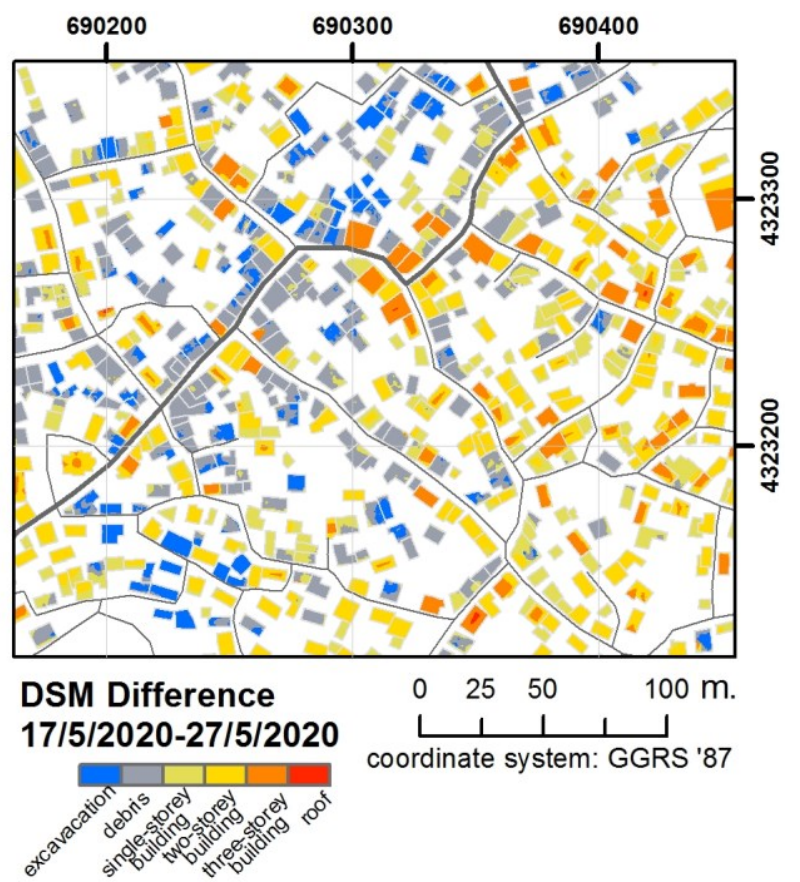

Figure 7. DSM difference map between $29^{\text {th }}$ September 2019 and $17^{\text {th }}$ May 2020. It clearly presents the changes occurred and more specifically the buildings that were demolished, as well the number of floors of the buildings that were not damaged.
The cartographic visualization of the estimated volumes, on the four dates, aims to document the progress of the postearthquake recovery phase of the settlement.

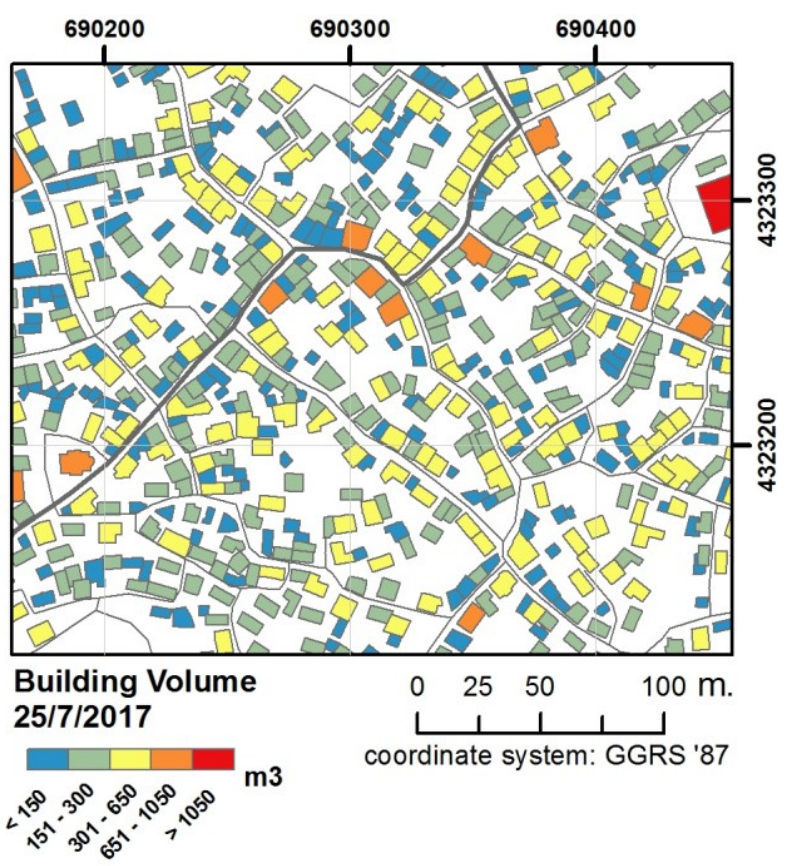

Figure 8. Building volume map of 25/07/2017.

More analytically, five categories can be distinguished:

- The first category present building volume values up to 150 cubic meters, which concerns mainly to small single-storey buildings with roofs, which present a significant number due to the traditional character of the settlement.

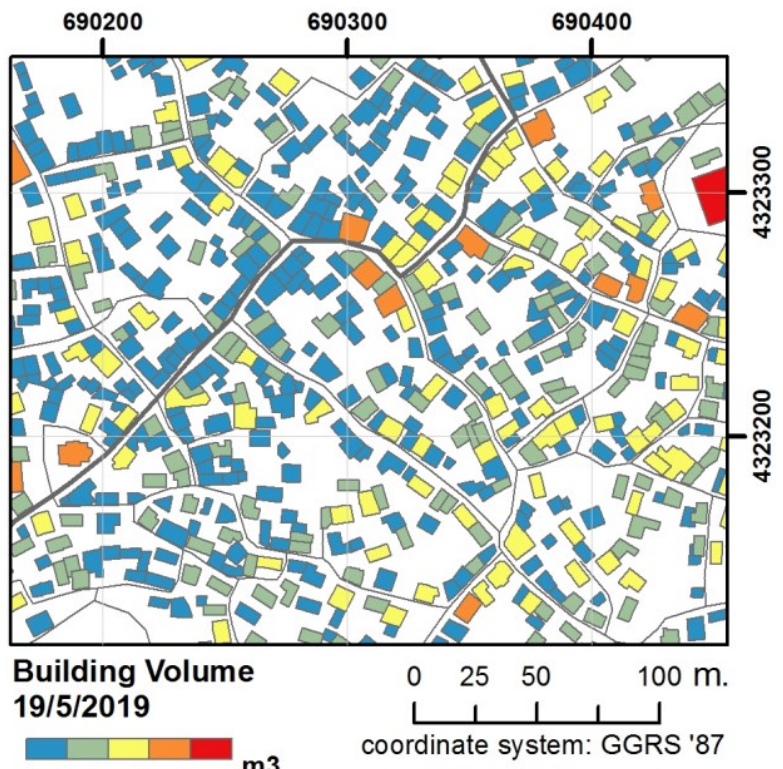

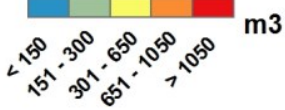

Figure 9. Building volume map of $19^{\text {th }}$ May 2019.

- The second category present buildings with volume values up to 300 cubic meters and concerns mainly medium-sized single-storey buildings with roofs, which 
also present a significant number due to the traditional character of the settlement.

- The third category present several buildings having volume values ranging from 300 up to 650 cubic meters and concerns medium-sized two-storey buildings with roofs while the fourth category with volumes up to 1050 refers to a small number of three-storey buildings in a large two-storey house with roofs.

- The fourth category present few buildings having volume values ranging from 650 up to 1050 cubic meters and concerns medium-sized three-storey buildings with roofs or large size two-storey houses with roofs.

- Finally, buildings with a particularly large volume of more than 1050 cubic meters are the school and the large temple of the village.

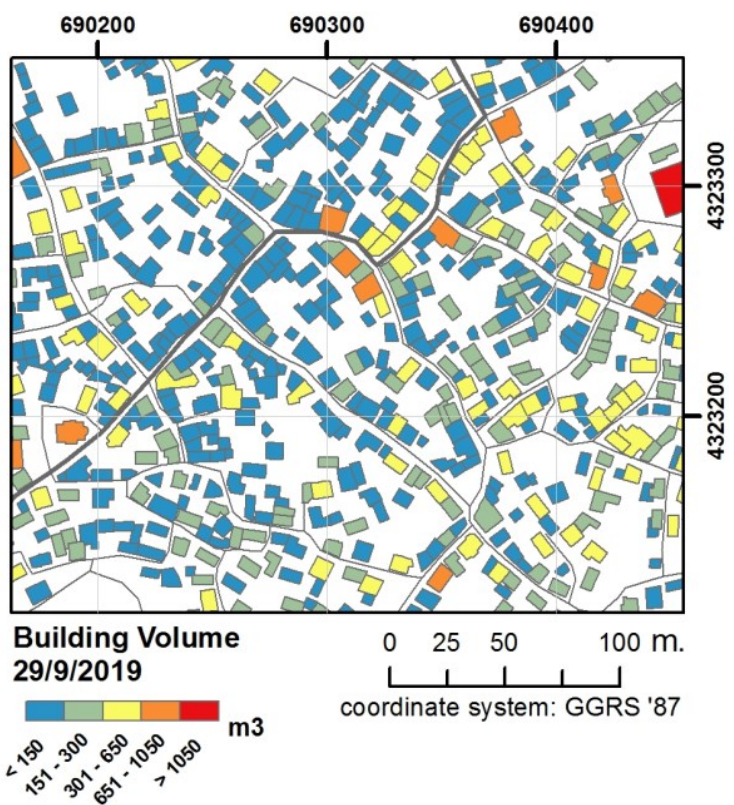

Figure 10. Building volume map of $29^{\text {th }}$ September 2019.

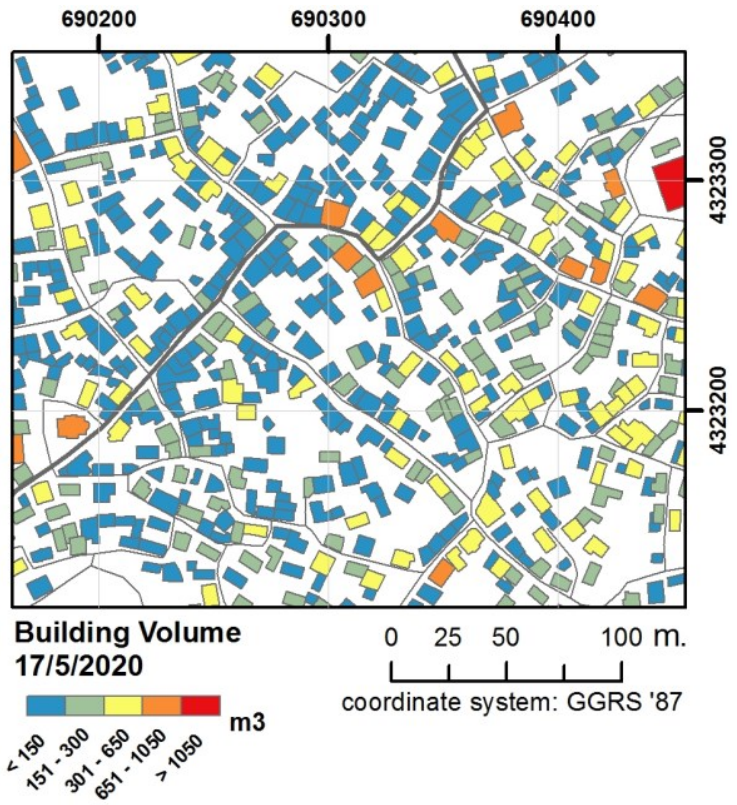

Figure 11. Building volume map of $17^{\text {th }}$ May 2020.

\subsection{Evaluation of the results}

The evaluation of the results obtained from the application of the proposed methodology was carried out with field work, which took place on the same dates of the UAS image acquisition flights. More specifically, the fieldwork concerned the visual assessment - confirmation of the condition of the buildings, classifying them into the following categories: a) buildings that remained unchanged, b) buildings that were demolished and c) new buildings that were rebuilt.

\begin{tabular}{|c|c|c|c|}
\hline & \multicolumn{3}{|c|}{ Date } \\
\hline Demolished & $19 / 05 / 2019$ & 29/09/2019 & $17 / 05 / 2020$ \\
\hline $\begin{array}{l}\text { one-storey } \\
\text { buildings }\end{array}$ & 114 & 13 & 8 \\
\hline $\begin{array}{l}\text { two-storey } \\
\text { buildings }\end{array}$ & 144 & 15 & 9 \\
\hline $\begin{array}{l}\text { three-storey } \\
\text { buildings }\end{array}$ & 5 & 0 & 0 \\
\hline Total & 253 & 28 & 17 \\
\hline rebuilded & 2 & 0 & 9 \\
\hline
\end{tabular}

Table 2. Field work observation results concerning the number of building that have been demolished and/or rebuilded at the three dates of flight campaigns.

The application of the above-described methodology are confirmed by the field work observation results with great accuracy as we see in the Table 2 and analyzed in the following chapter.

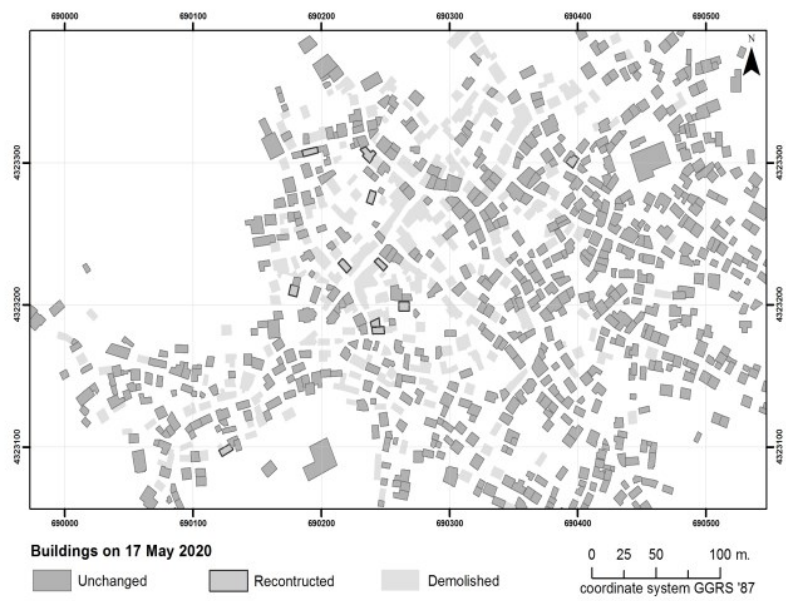

Figure 12. Map presenting the progress of the post-earthquake recovery phase on $17^{\text {th }}$ May 2020 , as derived by field observation.

\section{RESULTS AND DISCUSSION}

By applying the above-described methodology and updating the results that emerged from it, it is possible to monitor the evolution of the recovery phase process over time after the earthquake that damaged the buildings of Vrisa. Especially for this traditional settlement we observe the following cases (Figure 13):

- Buildings that did not present changes in time: this is a significant number of buildings in the 
settlement which either did not suffer any serious damage or suffered very light damages (damage categories 1 and 2 according to the EMS-98) and consequently these damages did not make it demolishable. It is worth noting that this category also includes several buildings which, while they have suffered more serious damage, however, their owners did not carry out restoration procedures through demolition (Figure 13-unchanged).

Buildings that were demolished: this is a critical number of buildings in the settlement which, due to the seriousness of the damage suffered by the earthquake, were demolished either until May 2019 or later. In the Figure 13-dimolished 1 we see the buildings that existed until September 2019 and demolished in the next period, until May 2020. In Figure 13-dimolished 2 we see the buildings that existed until May 2019 and demolished in the next period, during the summer, until September 2019.

Buildings that are being rebuilt: this is a limited number of buildings that are being rebuilt in the settlement. The following cases are distinguished: a) buildings that were built in a very short period of time (one year) changing not only the construction materials but also the original design and area - form of the building (Figure 13-rebuilded 1), b) buildings that have just begun excavations for their construction (Figure 13-rebuilded 2), c) buildings that were built and retain the original plan and area (Figure 13rebuilded 3).

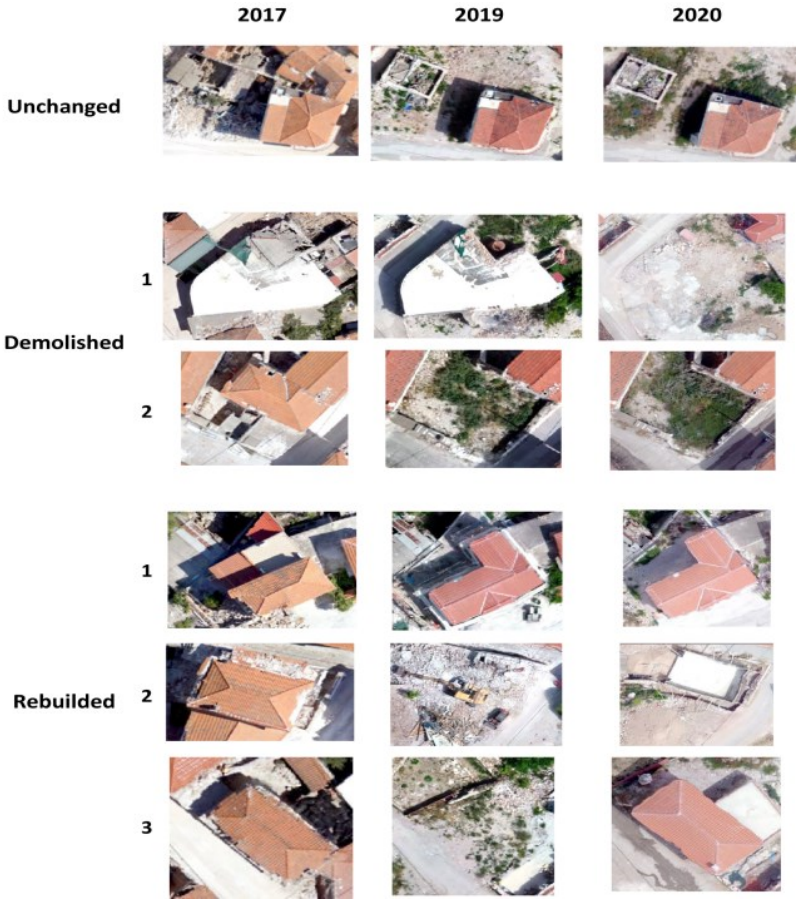

Figure 13. The evolution of the recovery phase process buildings during the three (3) flight campaigns with UAS, that took place in Vrisa between 2017 and 2020.

These categories of buildings are also presented in the following charts created based on the volumes of the buildings for the periods between the three (3) flight campaigns that took place in Vrisa, applying the described methodology. In more detail (Figure 14):
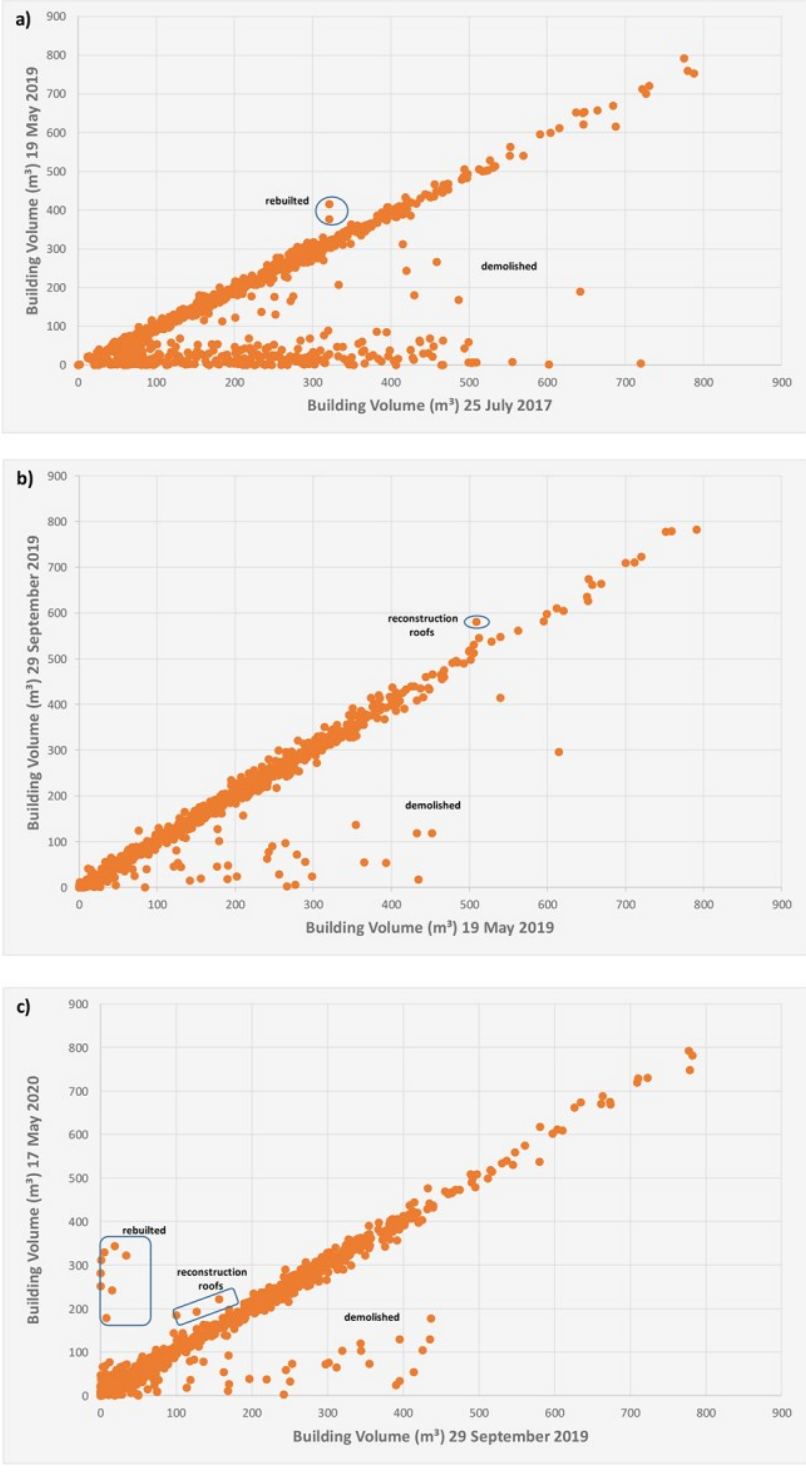

Figure 14. Buildings volume charts which clearly shows the demolition and rebuilt process between the three (3) flight campaigns with UAS, that took place in Vrisa between 2017 and 2020 .

- In the volume chart (a), between July 2017 and May 2019 , the large number of demolitions, 253/340, are found, mainly of small volume of buildings that constitute the majority of the buildings due to the traditional character of the settlement of the island of Lesvos. The same diagram shows the early two buildings that were rebuilted shortly after the earthquake effect. The diagonal shows the buildings that were not damaged, while below the diagonal are the buildings that were demolished. Above the diagonal are the two buildings were rebuilted, as also shown in Table 2.

- In the volume chart (b), between May 2019 and September 2019, there is a reduced number of demolition of buildings that have been severely damaged by the earthquake and without the construction of new buildings. The small increase in the volume of a small number of buildings is due to the reconstruction of the roof, which was either 
severely damaged or collapsed. The roof is a basic feature of the buildings due to the traditional character of the settlement on the island of Lesvos. In this diagram it can be seen that the results are almost identical with the application of the above-described methodology with the results from the field work, as shown in Table 2.

- In the volume chart (c), between September 2019 and May 2020, we observe that demolition continues at a slow pace. At the same time, the construction of buildings has begun, which have largely completed their static frame, as well as the reconstruction of roofs in buildings that had not been severely damaged (damage categories 3 according to the EMS-98). This volume chart shows the nine (9) new buildings that rebuilt, the small number of the reconstruction roofs, as well as the small number of buildings that were demolished, all with great accuracy in relation to Table 2. Changes in volumes smaller than $100 \mathrm{~m}^{3}$ are due to the gradual removal of debris from destroyed buildings.

\section{CONCLUSIONS}

The exploitation of the UAS technologies undoubtedly confers a strong advantage on the effort to develop innovative methodologies for the multitemporal monitoring and 3D mapping of the recovery phase of an earthquake - affected settlement. Especially for the cases of traditional settlements, where special emphasis is given to the preservation of its traditional character, the results produced, having highresolution and accuracy, are a very basic tool for all stakeholders and persons involved.

In the present study, the methodology developed and applied for $3 \mathrm{D}$ mapping of the changes that took place until May $17^{\text {th }}$ 2020, achieves reliable results in a relatively easy, fast and economically feasible way. By applying the above-described methodology, it was possible to monitoring the recovery phase during July 2017 and May 2020 which 302/340 buildings that had been severely damaged by the earthquake have been demolished. A small number of new buildings eleven (11) have also been rebuilded and small number of buildings (about 5) that have just begun excavations for their construction. An important parameter for obtaining reliable data and comparable results is the proper selection of flight parameters and their maintenance at all epochs when the data collection is decided. The flight height, flight speed, the front overlapping and the side overlapping are the most important parameters in the flights. The above methodology proved that shooting video or images does not affect the creation of DSM, neither the calculation of the buildings volumes.

The experience obtained from this research can be further exploited in the near future, focusing on the automation of the proposed methodology, in order to further accelerate the achievement of reliable results without the intermediate interpretation of the orthophoto-maps.

\section{ACKNOWLEDGEMENTS}

This research is co-financed by Greece and the European Union (European Social Fund- ESF) through the Operational Programme «Human Resources Development, Education and Lifelong Learning 2014-2020» in the context of the project "Development of 3D semantic models in 3D mapping and geovisualization of earthquake effects in a traditional settlement" (MIS 5047141).

\section{REFERENCES}

Adams, S.M. and Friedland, C.J., 2011. A survey of unmanned aerial vehicle (UAV) usage for imagery collection in disaster research and management, In: 9th International Workshop on Remote Sensing for Disaster Response, Stanford University, California, USA. Agisoft, 2018.

Agisoft PhotoScan User Manual, Professional Edition, Version 1.3, http://www.agisoft.com/pdf/photoscan-pro_1_3_en.pdf (7 February 2018).

Baiocchi V., Dominici D., Giannone F. and Zucconi M., 2012. Rapid building damage assessment using EROS B data: the case study of L'Aquila earthquake. European Journal of Remote Sensing - 2012, 44 (1): 153-165.

Chatzipetros, A., Kiratzi, A., Sboras, S., Zouros, N., and Pavlides, S., 2013. Active faulting in the north-eastern Aegean Sea Islands. Tectonophysics, 597-598, pp. 106-122.

Dominici, D., Alicandro M., and Massimi, V., 2017. UAV photogrammetry in the post-earthquake scenario: case studies in L'Aquila. Geomatics, Natural Hazards and Risk, 8(1), pp. 87$103 \mathrm{https}$ //doi.org/10.1080/19475705.2016.1176605.

Grünthal, G. (ed) 1998. European Macroseismic Scale 1998 (EMS-98). Chaiers du Centre Européen de Géodynamique et de Séismologie, 15, Luxembourg.

Huang, H, Long, J, Yi, W, Yi, Q, Zhang, G, and Lei, B., 2017. A method for using unmanned aerial vehicles for emergency investigation of single geo-hazards and sample applications of this method. Natural Hazards and Earth System Sciences, 17(11), pp. 1961-1979 https://doi.org/10.5194/nhess-17-19612017.

Kiratzi, A., 2018. The 12 June 2017 Mw 6.3 Lesvos Island (Aegean Sea) earthquake: Slip model and directivity estimated with finite-fault inversion. Tectonophysics, 724-725, pp. 1-10 https://doi.org/10.1016/j.tecto.2018.01.003.

Lekkas, E., Carydis, P., Skourtsos, E., Mavroulis, S., Andreadakis, E., Antoniou, V. and Spyrou, N, 2017. Factors controlling the distribution of building damage in the traditional Vrissa settlement induced by the 2017 June 12, Mw 6.3 Lesvos (Northeastern Aegean Sea, Greece) earthquake. In: 8th International INQUA Meeting on Paleoseismology, Active Tectonics and Archeoseismology (PATA), 13-16 November, 2017, New Zealand.

Novak, I. and Soulakellis, N., 2000. Identifying geomorphic features using LANDSAT-5/TM data processing techniques on Lesvos, Greece. Geomorphology, 34(1-2), pp. 101-109 https://doi.org/10.1016/S0169-555X(00)00003-9.

Papadimitriou, P.; Kassaras, I.; Kaviris, G.; Tselentis, G.-A.; Voulgaris, N.; Lekkas, E.; Chouliaras, G.; Evangelidis, C.; Pavlou, K.; Kapetanidis, V.; et al. The $12^{\text {th }}$ June $2017 \mathrm{Mw}=6.3$ Lesvos earthquake from detailed seismological observations. J. Geodyn. 2018, 115, 23-42.

Snavely, N., 2011. Scene reconstruction and visualization from Internet photo collections. IPSJ Transactions on Computer Vision and Applications, 3, pp. 44-66.

https://doi.org/10.2197/ipsjtcva.3.44 
Snavely, N., Seitz, S.M., and Szeliski, R. 2008. Modeling the world from Internet photo collections. International Journal of Computer Vision, 80(2), pp. 189-210.

https://doi.org/10.1007/s11263-007-0107-3

Soulakellis, N., Novak, I., Zouros, N, Lowman, P. and Yates, J. 2006. Fusing Landsat-5/TM imagery and shaded relief maps in tectonic and geomorphic mapping: Lesvos Island, Greece. Photogrammetric Engineering and Remote Sensing, 72(6), pp. 693-700.

Soulakellis, N.; Tataris, G.; Papadopoulou, E.; Chatzistamatis, S.; Vasilakos, C.; Kavroudakis, D.; Roussou, O.; Papakonstantinou, A. Synergistic Exploitation of Geoinformation Methods for Post-earthquake 3D Mapping and Damage Assessment. In Intelligent Systems for Crisis Management; Altan, O., Chandra, M., Sunar, F., Tanzi, T.J., Eds.; Lecture Notes in Geoinformation and Cartography; Springer International Publishing: Cham, 2019; pp. 3-31 ISBN 978-3-030-05329-1.

Papakonstantinou, A.; Doukari, M.; Roussou, O.; Drolias, G.C.; Chaidas, K.; Moustakas, A.; Athanasis, N.; Topouzelis, K.; Soulakellis, N. UAS multi-camera rig for post-earthquake damage 3D geovisualization of Vrisa village. In Proceedings of the Proceedings of SPIE - The International Society for Optical Engineering; 2018; Vol. 10773.

Triggs, W., McLauchlan, P., Hartley, R., and Fitzgibbon, A., 1999. Bundle adjustment: A modern synthesis. In: Vision Algorithms: Theory and Practice, number 1883 in LNCS. Springer-Verlag. Corfu, Greece, pp. 298-373.

Tong X., Hong Z., Liu S., Zhang X., Xie H., Li Z., Yang S., Wang W., and Bao F. Building-damage detection using pre- and post-seismic high-resolution satellitestereo imagery: A case study of the May 2008 Wenchuan earthquake. ISPRS Journal of Photogrammetry and Remote Sensing 68 (2012) 13-27.

Vasilakos, C.; Chatzistamatis, S.; Roussou, O.; Soulakellis, N. Comparison of Terrestrial Photogrammetry and Terrestrial Laser Scanning for Earthquake Response Management. In Intelligent Systems for Crisis Management; Altan, O., Chandra, M., Sunar, F., Tanzi, T.J., Eds.; Lecture Notes in Geoinformation and Cartography; Springer International Publishing: Cham, 2019; pp. 33-57 ISBN 978-3-030-05329-1.

Wegscheider, S., Schneiderhan, T., Mager, A., Zwenzer, H., Post, J., Strunz, G., 2013. Rapid mapping in support of emergency response after earthquake events. Natural Hazards, 68(1), pp. 181-195 https://doi.org/10.1007/s11069-013-0589-y

Westoby, M.J., Brasington, J, Glasser, N.F., Hambrey, M.J., and Reynolds J.M., 2012. Structure-from-motion' photogrammetry: A low-cost, effective tool for geoscience applications. Geomorphology, 179, pp. 300-314.

Xu, Z., Yang, J., Peng, C., Wu, Y., Jiang, X., Li, R., Zheng, Y., Gao, Y., Liu, S., Tian, B., 2014. Development of an UAS for post-earthquake disaster surveying and its application in Ms7.0 Lushan Earthquake, Sichuan, China. Computers and Geosciences, 68, pp. 22-30.

https://doi.org/10.1016/j.cageo.2014.04.001 